\title{
Differences in assessment methods of face-to-face and online learning
}

\author{
Nadezhda Mamatkulovna Glushkova ${ }^{*}$, Karine Henrickovna Apresyan, Daria \\ Aleksandrovna Mironova, Tatiana Nikolaevna Lyubimova, and Natalya Vladimirovna \\ Chernyishkova
}

Financial University under the Government of the Russian Federation, Department of Foreign Languages and Intercultural Communication, Moscow, Russia

\begin{abstract}
The article is devoted to the study of differences in assessment methods of face-to face and online learning of a foreign language in higher education, in particular, the issue of the effectiveness of the assessment techniques used in different formats. Numerous questions that accompanied foreign language online learning in 2019-2020 and 2020-2021 academic years, as well as contradictory reviews about the assessment methods of students' knowledge were the prerequisites of the study. The experience demonstrated that online learning differs significantly from face-to-face learning in a number of requirements for teachers and students. The aim of the study is to modify traditional methods of students' knowledge evaluation and assessment in the form of credits or examinations towards greater independence and objectivity and achieve the autonomy of the assessment process. We carried a survey of students' opinions on the effectiveness of the forms of assessment adopted at the higher education. Based on the survey results, recommendations are made for improving methods of students' knowledge assessment system with respect to the educational format. The conclusions made on the basis of data analysis provide a number of changes in the methods of online assessment both in the educational process at higher education and in staff training programs.
\end{abstract}

Keywords: assessment methods and techniques, higher education, face-to-face and distance education, full-time learning, online learning, false interaction

\section{Introduction}

The issue of effective and objective methods for evaluating students' knowledge in higher education is an urgent challenge today. Though the benefits of using innovative technologies in education are obvious, their contradictory impact on traditional face-to-face education process became noticeable during the 2019-2020 and 2020-2021 academic years, when the educational format was transformed from face-to-face to online. The wide variety

*Corresponding author: nmglushkova@fa.ru 
of tools and technology of distance learning allowed to carry out educational process during COVID-19 pandemic. A range of scientific works presented modernized ways of education in the new reality [1-8] It has become evident, that such educational services and video conferencing applications as Skype, Zoom, WebEx, Hangouts, Microsoft Teams and Moodle are capable of maintaining education at the proper level [9]. Flexibility, adaptability and personalization of the education system became the key advantages of distance learning and the educational process reached a qualitatively new level [10].

The new format has its share of obvious advantages and delayed negative consequences. Students are assigned to a considerable share of responsibility for the quality of remote classroom work, the objectivity of testing, and the adequacy of time and effort distribution [11]. Another challenge of distance education is lack of social interaction and the loss of incentive in the form of a dialogue or polylogue. Students' low motivation, poor academic performance and low emotional involvement in the learning process are the consequences of distance education. [12, 13].

The above-mentioned factors indicate an obvious contradiction between the expectations and the reality of distance education. As a result, the quality of the end-of-course knowledge varies significantly and directly depends on many factors (self-discipline, computer proficiency, software, etc.) [14]. This contradiction is clearly observed at the stage of student's knowledge assessment.

Examination in a form of a written test is traditionally considered the main evaluation method of learning abilities and academic performance of the student. The advantages of this method include the development of culture of thinking and verbal self-expression. Students' written work clearly demonstrates the ability to express ideas logically and adequately. $[15,16]$. However, the paradigm of a written assessment in all its diversity is currently losing its position in favor of oral assessments [17]. Thus, we note the change in the forms of control caused by a number of prerequisites. During the distance learning the inevitable use of digital technology and Internet resources evidently facilitated the educational process, but often provoked academic fraud among university students. The established format of any evaluation method and students' knowledge assessment with a significant written part and a less significant oral or creative component, does not meet current conditions. In this case, we observe a short-term falseointeraction (false interaction) which is a form of social interaction in which participants imitate proper behavior. The peculiarity of this kind of behavior is that both participants understand the falsity of the action or result, but for mutual benefit or tranquility, they take the distortion for reality [18]. It was observed during the distance examination when students widely used online resources, messenger platforms and auxiliary applications. In this case the technical competence of students was destructive and entailed far-reaching negative consequences $[19,20]$.

Due to the results of the 2019-2020 and 2020-2021 academic years, it seems crucial to take a fresh look at students' knowledge assessment methods in higher education. The ability to interact effectively in future will increase the demand for graduates in their professional areas [21, 22]. Thus, the issue of creating more flexible and adaptive evaluation system adapted to the new learning format with the preserved element of challenge and complexity becomes particularly relevant.

\section{Methods}

This article aims to provide a comparative analysis based on the findings of a student survey on the objectivity and efficiency of various assessment methods in distance and 
full-time education. As a basis for the analysis, the authors used the experience of students' knowledge testing during the 2019-2020 summer exam session and the 2020-2021 winter exam session in the subject of Foreign language at the Faculty of Economics and Business, Financial University under the Government of the Russian Federation. The evaluative survey was conducted with four groups of respondents, in the range from the 1 st to the 4th course with an online learning experience. The working hypothesis was that part of the traditional assessment techniques loses relevance during distance education. We compared the answers to the questions about various types of students' knowledge evaluation in online and full-time education formats. We may assume that the research results will increase the efficiency of knowledge testing and serve students' greater motivation since their views can be considered to modify and improve students' knowledge assessment methods.

The questions formulated in the survey allowed the participants to select more than one response:

1-4) What type of written assessment / oral assessment would be the most effective technique to measure student knowledge and skills in full-time education/ online learning? It is necessary to clarify that the answer "written assessment" included all the variety of forms of students' creative writing activity. "Referring of an audio and written text" was chosen as a separate assessment technique since the basis of it is the ability to understand the main idea of audio or printed text and convey it in a particular form. Answers to questions devoted to oral part contribute to understanding how confident a student feels about spontaneous real-life communication and his professional competencies. Further, in questions 5-11, students and teachers were asked to rate the objectivity of assessment methods on a scale from 1 to 5 .

\section{$3 \quad$ Results and discussion}

Respondent data let us identify the following trends and reveal a number of key findings.

The analysis of the most objective types of written assignments demonstrated that a written assessment in all its forms is prevalent among students' preferences in both learning formats. Figure 1 shows that a written assessment technique has a higher objectivity level in distance rather than face-to-face learning, according to students' opinions. A vocabulary and grammar test traditionally placed at the beginning of a mid-semester or final examination paper has a certain weight in full-time education. However, in online learning, its value is slightly higher than referring of an audio and written text. 


\section{Full-time education}

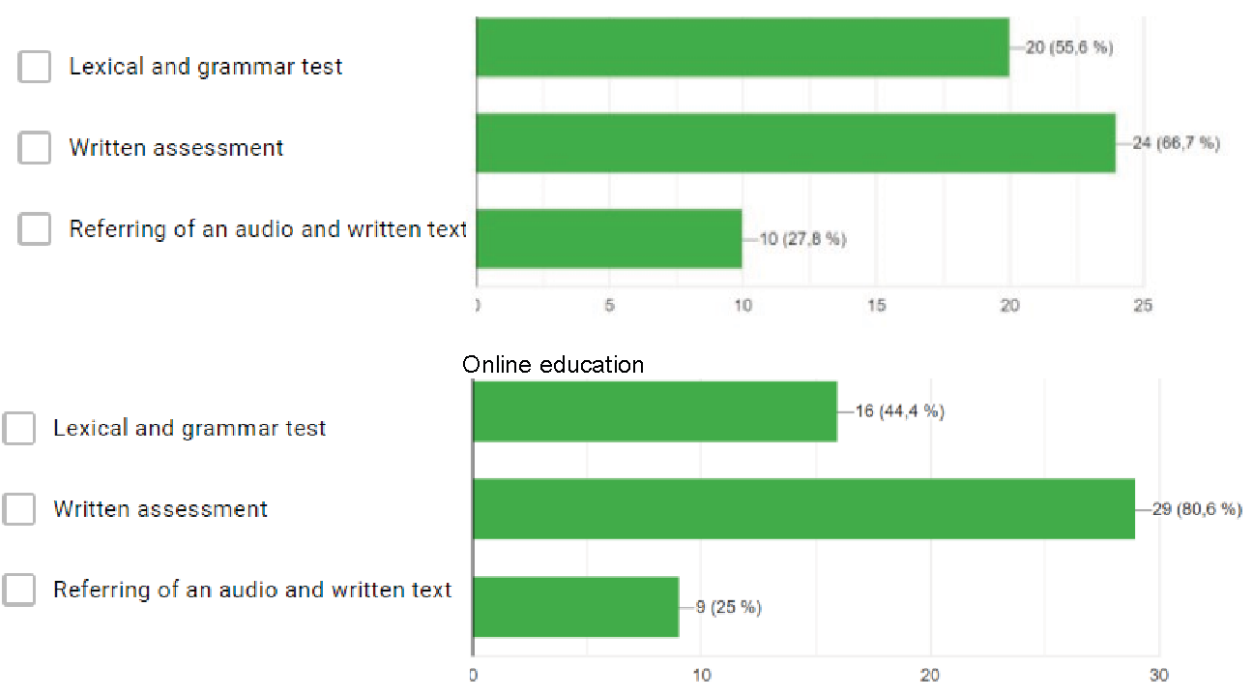

Fig. 1. The objectivity evaluation of the written assessment technique depending on the learning format.

The students' evaluation of written assessment methods and their efficiency used a scale from 1 to 5. A majority of respondents rated a lexical and grammar test with a score of four. Then in descending order, the students gave it a score of three (see Fig. 2). The survey revealed that a written assessment technique (in the form of an essay, an extended answer to the question, writing a business letter, writing a summary, analyzing a graph) generally scored higher (scores of 5 and 4). Compared with the assessment techniques mentioned earlier, referring of an audio and written text is considered a less popular method: the most frequent score given is 3 , followed by 4 and 2 , respectively. 


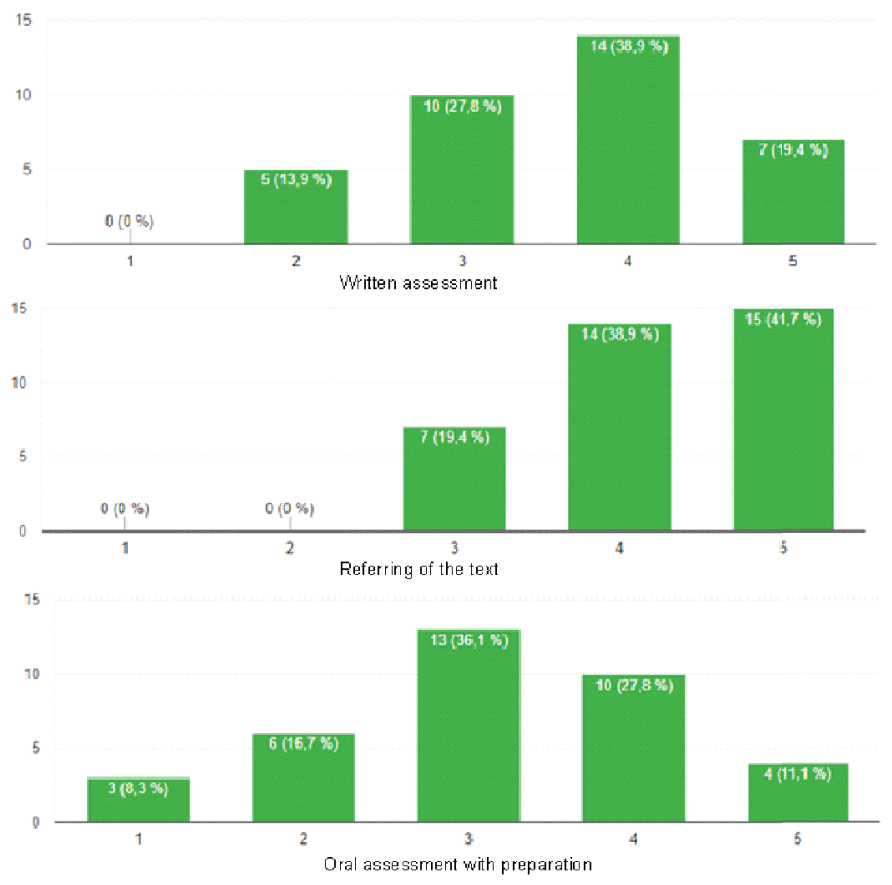

15

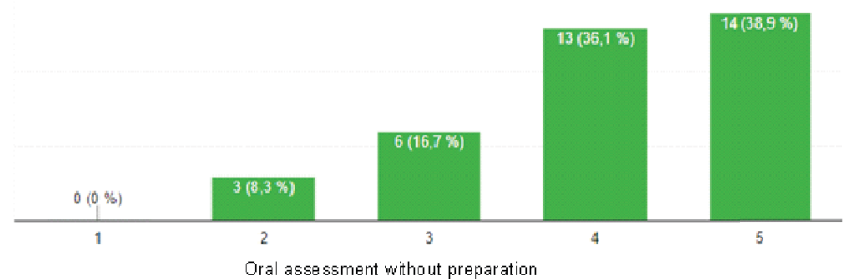

15

Oral assessment without prepar ation

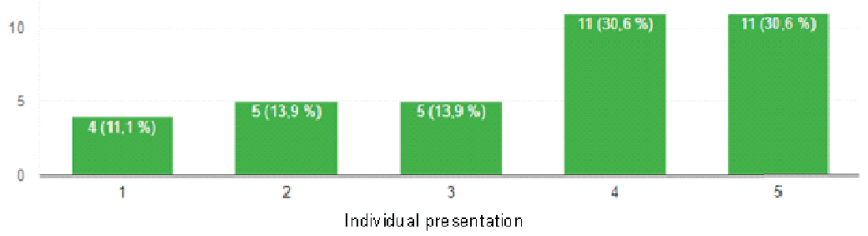

15
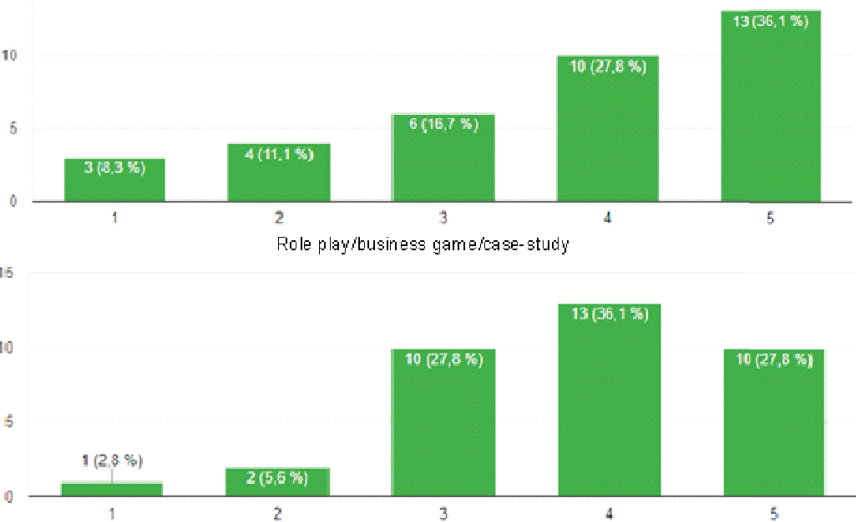
Fig 2. The ratio of control types and their evaluation by students.

Preliminary findings concerning the written methods of assessment suggest a higher weight of the creative component in students' opinion. First, a written assessment gives them freedom of expression and demonstrates their skills. Second, even in distance learning, a written assessment gives an adequate knowledge and skills evaluation in the respondents' opinion. Third, in the authors' opinion, referring of an audio and written texts was rated the last not because of its low didactic value. Students probably do not see the special practical significance of such a written assignment technique. Another reason may lie in the complexity of this format, poor knowledge of referring techniques, the need to follow official framework.

The respondents' choice of the most preferred oral assessment technique allows us to draw several conclusions (see Fig. 3). During full-time education, students highly appreciated the objectivity of three assessment techniques: an oral assessment with preparation, individual presentation, role-play, and business game. The students positively evaluated the objectivity of many oral assessment techniques. The participants' answers differed in distance learning. The highest priority was given to an individual presentation as a mix of linguistic, visual, and creative components. It is important to note a decrease in the efficiency of a business game or a role-play during online learning. Dependency on technical reasons makes communication in the group unstable.

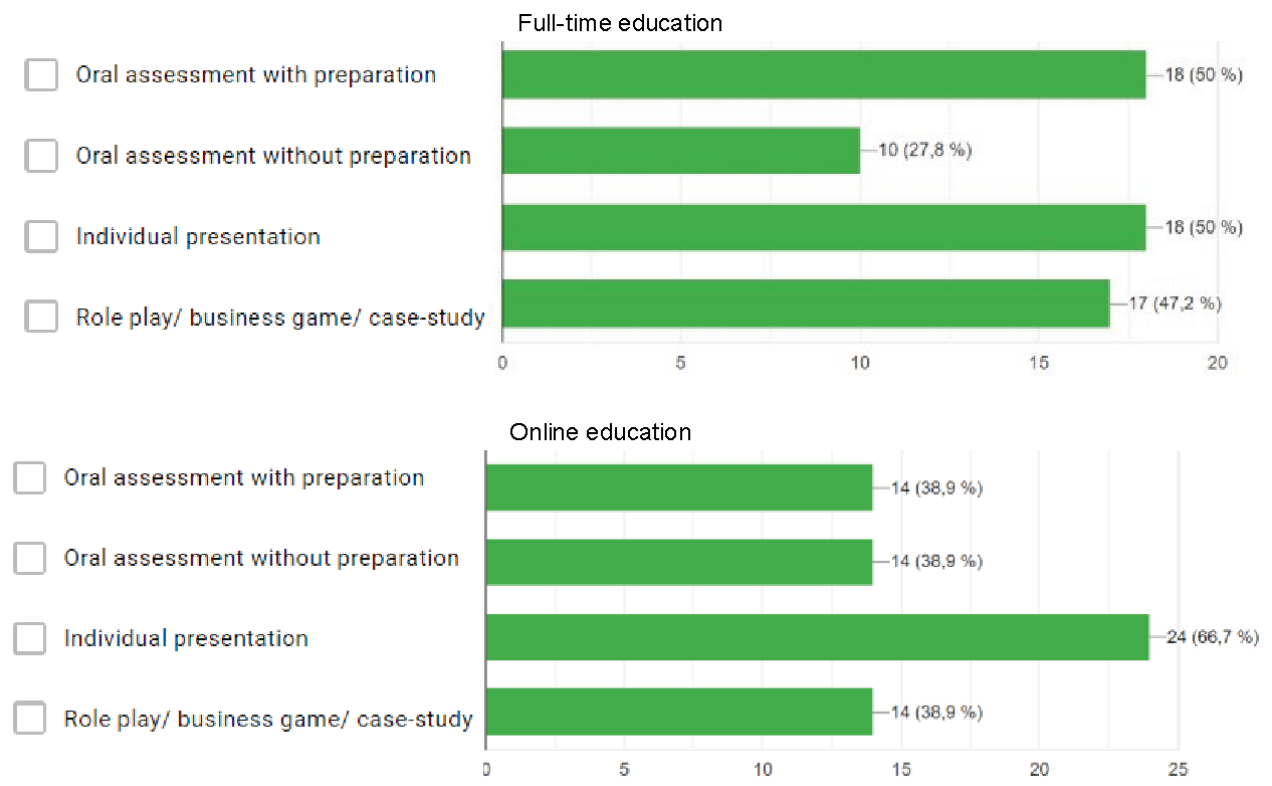

Fig. 3. The objectivity evaluation of the oral assessment technique depending on the learning format.

The ratio of assessment methods demonstrated the highest score of the methods of an oral assessment with preparation (grades 5 and 4 correspond to $38 \%$ and $36 \%$ ) and an individual presentation ( 5 and 4 correspond to $36 \%$ and $27 \%$ ). Business game, role play or case study occupy the third position according to the objectivity evaluation (grade 4 prevails in $36 \%$ ).

The option of an oral assessment without preparation has its certain weight. Its great relevance in the distance education is quite noticeable. Spontaneous speech occupied the 
fourth place, but its value by students is not much lower than other options: $30 \%$ of students rated it with grades 5 and 4 .

The results concerning the oral part let us suggest that during the full-time education, students are generally satisfied with the oral answer options and confirm their objectivity. In the distance education, however, students tend to prefer presentations due to the convenience and diversity of the visual form. Other types of oral assessment in the online education are less objective from the respondents' point of view. The second conclusion is the most ambiguous and alarming, as the lower popularity of an unprepared answer indicates the students' uncertainty of their spontaneous speech, whereas it is one of the main competencies of professional education.

\section{Conclusion}

We can apply this survey in different ways. It is worth taking into account the answers of students regarding their preferences, especially in the online education. In most cases the respondents are more aware of the objectivity of a particular type of assessment than the teacher, and their opinion better reflects the real situation. Further, it seems correct in terms of teaching to focus on the greatest difficulty for students and work on it.

The least frequent options were: an oral assessment without preparation and referring the text. It possibly means that as the studying material becomes more complex and the level of students' language increases, these two options should be in focus during the examination. Thus, if the control strategy combines the most and least popular options for oral and written statement, then it simultaneously reveals the potential of the student and retains an element of challenge and complexity. This research may be applied both in the training of higher school students, and in professional development programs, that are often carried out online.

\section{References}

1. B. Beason-Abmayr, D.R. Caprette, Ch. Gopalan, Adv Phys Edu, 45, 384-389 (2021). https://doi.org/10.1152/advan.00248.2020

2. J.Ch. Chan, As the computer was turned on: a case study of computer-mediated educational experience in an ESL classroom, $\mathrm{PhD}$ thesis (UO Libraries, Eugene, 1992)

3. J. Gillett-Swan, J Learn Design, 10(1), 20-30 (2017). http://dx.doi.org/10.5204/jld.v9i3.293

4. J.J. Green, C.C. Stone, A. Zegeye, J Edu Bus, 89(1), 20-26 (2013). https://doi.org/10.1080/08832323.2012.749206

5. K.R. Lima, et al., Adv Phys Edu, 44, 679-683 (2020). https://doi.org/10.1152/advan.00131.2020

6. L. Ortman, KDP New Teacher Advocate, 14-15 (2017)

7. E. Slover, J. Mandernach, J Edu Online, 15, 1 (2018)

8. P.J. Vollbrecht, K.A. Porter-Stransky, W.L. Lackey-Cornelison, Adv Phys Edu, 44, 722-725 (2020). https://doi.org/10.1152/advan.00140.2020

9. A.V. Ponachugin, Bul Mininsk Univ, 8(4), 6 (2020). https://doi.org/10.26795/2307-1281-2020-8-4-6 
10. E.I. Okhrimenko, Osobennosti distantsionnogo obucheniya v vysshei shkole: metody $i$ tekhnologii obucheniya [Features of distance learning in higher education: methods and technologies of education], in New educational technologies in higher education: materials of the X International scientific and methodological conference (Ekaterinburg, 2013)

11. S.V. Matvienko, et al., Edu Law, 1, 195-199 (2021). https://doi.org/10.24411/2076-1503-2021-00032

12. O.V. Kononikhina, Int J Human Nat Sci, 2-1, 107-111 (2021). https://doi.org/10.24412/2500-1000-2021-2-1-107-111

13. D.V. Agaltsova, et al., Vyzovy sistemy obrazovaniya v epokhu tsifrovoi ekonomiki: matritsa vozmozhnostei [Challenges of the education system in the era of the digital economy: a matrix of opportunities], M.V. Melnichuk, I.I. Klimova (eds) (Scientific technologies, Moscow, 2020)

14. I.V. Gordeeva, Azimuth Sci Res: Pedag Psy, 10(1(34)), 61-64 (2021). https://doi.org/10.26140/anip-2021-1001-0013

15. B.S. Kubekova, Prob Mod Pedag Edu, 63-4, 131-134 (2019)

16. N.V. Ukanakova, Chelyabinsk Human, 3(36), 51-63 (2016)

17. V.P. Arefyev, et al., Open Dist Edu, 1(77), 31-37 (2020). https://doi.org/10.17223/16095944/77/5

18. M.V. Kashirina, Soc Power, 6(44), 11-16 (2013)

19. E.V. Ganina, et al., Int J Eng Adv Tech, 9(1), 5565-556 (2019)

20. N.M. Glushkova, Electronic dictionaries and translators as part of the learning process of a modern student: how to stop fighting and start benefiting, in Stimulating the innovative development of the company in the strategic period, 155-160 (2018)

21. E.A. Fedorova, et al., Int J Eng Adv Tech, 9(1), $4532-4535$ (2019)

22. N.V. Chernyshkova, Phil Sci. Quest Theory Pract, 7(13), 321-325 (2020). https://doi.org/10.30853/filnauki.2020.7.64 